\title{
Long-Term Effects of Adenotonsillectomy on Growth and Symptoms in Childhood
}

\author{
Woo Sung Park, Yong Bae Ji, Seung Hwan Lee, \\ Jin Hyeok Jeong, Chang Myeon Song, and Kyung Tae \\ Department of Otolaryngology-Head and Neck Surgery, College of Medicine, Hanyang University, Seoul, Korea
}

\section{소아 성장 및 편도 비대 증상에 미치는 편도절제술의 장기 효과}

박우성 · 지용배 · 이승환 · 정진혁 · 송창면 · 태 경

한양대학교 의과대학 이비인후과학교실

Received March 27, 2018

Revised June 27, 2018

Accepted July 4, 2018

Address for correspondence

Yong Bae Ji, MD, PhD

Department of Otolaryngology-

Head and Neck Surgery,

College of Medicine,

Hanyang University,

222 Wangsimni-ro, Seongdong-gu,

Seoul 04763, Korea

Tel $+82-31-560-2297$

Fax $+82-31-566-4884$

E-mail jyb20000@hanyang.ac.kr
Background and Objectives This study was performed to evaluate the long-term effect of adenotonsillectomy on childhood growth by examining preoperative growth status and presenting symptoms.

Subjects and Method One hundred and four patients who underwent adenotonsillectomy from January to December 2009 were enrolled in this study. Clinical data were collected from medical record reviews and through the administered questionnaire. We investigated symptoms and growth changes during 5 years following the surgery.

Results The mean age of patients was $6.0 \pm 1.94$ years (range, $3-10$ ), with the male to female ratio of 62:42. Pre-operative symptoms were significantly improved after the surgery. The mean pre-operative height and weight percentiles were $53.6 \pm 27.4$ and $59.6 \pm 29.2$ at initial evaluation, and $67.1 \pm 26.4$ and $59.6 \pm 28.6$ at 5 years post adenotonsillectomy $(p<0.001, p=0.989)$, respectively. An increase in height percentile was more prominent in patients whose pre-operative height percentile was less than 50 compared to those with a percentile of 50 or more $(p<0.001)$. Weight percentile was significantly increased in those with the pre-operative weight percentile of less than 50 and decreased in patients with a percentile of 50 or more.

Conclusion Adenotonsillectomy has a positive effect on height growth in children with adenotonsillar hypertrophy, especially in patients whose height percentile is less than 50 . Weight gain also can be expected in preoperative low-weight children.

Korean J Otorhinolaryngol-Head Neck Surg 2018;61(12):681-5

Key Words Adenoidectomy · Child · Growth · Tonsillectomy.

\section{Introduction}

The palatine tonsils and adenoids are classified as mucosaassociated lymphoid tissues located at the entrance to the upper airway. Their main role is to protect the body from the entry of exogenous material and infectious organisms such

This is an Open Access article distributed under the terms of the Creative Commons Attribution Non-Commercial License (https://creativecommons.org/licenses/by-nc/4.0) which permits unrestricted non-commercial use, distribution, and reproduction in any medium, provided the original work is properly cited. as bacteria through mucosal sites, especially in childhood. ${ }^{1)}$ At birth, the tissue size is very small, but increases as the child grows reaching peak size and immune function at 2-5 years old. It then becomes smaller at puberty as other lymphoid organs change. ${ }^{2)}$ Normally, in children, the adenoid forms a soft mound on the roof and posterior wall of the nasopharynx, just above and behind the uvula.

Chronic upper airway obstruction in childhood, followed by tonsil and adenoid hypertrophy can cause sleep-disordered 
breath, obstructive sleep apnea, mouth breathing, daytime sleepiness and simple snoring. Complications such as hypertension, heart failure, nocturia, activity disorder or learning disorder can also develop. ${ }^{3-5)}$ Growth retardation is another possible complication due to increased energy consumption or decreased growth hormone secretion during sleep and pain or discomfort with eating due to inflammation and a narrow oropharyngeal space. ${ }^{6-8)}$

Because immune function or upper respiratory tract starts to decline after 3 years of age, adenotonsillectomy is thought to have no significant effect on the immune system. ${ }^{9)}$ So, tonsillectomy can be recommended as a first-line treatment in chronic cases. There have been many studies regarding the effects on growth pattern after childhood tonsillectomy, and some authors have reported that height and weight growth patterns normalized after tonsillectomy. ${ }^{10-13)}$ However, there are few studies on the long-term effects on growth or presenting symptoms. Furthermore, it is also unclear impact on growth according to preoperative growth status. Therefore, the present study was conducted to evaluate the long-term effects of adenotonsillectomy on growth according to preoperative growth status and symptoms.

\section{Subjects and Method}

\section{Patient population}

We retrospectively reviewed the medical records of 138 consecutive patients whose age was 10 or less among the patients who underwent adenotonsillectomy due to frequent upper respiratory infection (URI) or sleep apnea from January 2009 to December 2009. We performed telephone-based survey about height and weight at 5 years after the surgery in 2014 after obtaining approval from the Institutional Review Board of Hanyang University Guri Hospital (HYGU-2016-7014). Patients or their parents were also asked questions about frequency of upper respiratory infection, appetite and sleep apnea, and each parameter was scored using 5 verbal rating scale: absent (1), mild (2), moderate (3), severe (4), very severe (5). Patients who were not available to contact for survey with incomplete medical record and who had other pediatric or psychiatric disease that can influence on growth from the time of surgery to survey were excluded. Finally, 104 patients completed questionnaire and they were enrolled in this study. All of the patients were ethnically Korean.

\section{Analyzing procedures}

Height and weight percentile were calculated using Pediatric and Adolescent Standard Growth Chart provided by Korean Centers for Disease Control. ${ }^{14)}$ Pre-operative and post-operative height and weight percentiles and presenting symptoms were analyzed to determine whether there was a change in growth and symptoms. We analyzed the change in height and weight percentile between the pre-operative and 5 years after surgery. Pre-operative growth status was also considered when comparing pre-operative and post-operative growth percentiles. To evaluate whether there were differences in growth according to pre-operative growth status, patients were divided into two groups: pre-operative height and weight percentile 50 or more and less than 50 .

\section{Statistical analysis}

We used SPSS 22.0 software for Windows (IBM Corp., Armonk, NY, USA). Values are presented as mean \pm standard deviation unless otherwise indicated. The paired t-test and student's t-test were used to evaluate differences. Differences were considered significant at $p<0.05$.

\section{Results}

\section{Patient population}

The subjects included 62 males and 42 females. Mean age was $6.0 \pm 1.9$ years (range, $3-10$ ) and mean follow up period was 63 months (range, 61-68). Mean pre-operative height was $119.13 \pm 12.94 \mathrm{~cm}$, and mean post-operative height was $155.29 \pm 12.38 \mathrm{~cm}$. Mean pre-operative weight was $24.88 \pm$ $8.47 \mathrm{~kg}$, and mean post-operative weight was $46.32 \pm 11.55$ $\mathrm{kg}$. The most common presenting symptom was snoring or sleep apnea in a total of 92 patients $(88.5 \%)$ with very severe (7 patients), severe (50 patients), moderate ( 21 patients), and mild (14 patients). Surgery was indicated in 12 patients (11.5\%) due to frequent upper respiratory infection. But, many patients had 2 or more symptoms. Frequent upper airway infections and poor appetite were noted in 64 patients $(61.5 \%)$ and 44 patients $(42.3 \%)$, respectively.

\section{Changes in symptoms}

All of preoperative presenting symptoms - frequency of upper airway infection, poor appetite and sleep disordered breathing - were significantly improved after surgery ( $p<$ $0.001, p<0.001$, and $p=0.002$, respectively) (Table 1 ). 


\section{Changes in height percentile}

The mean pre-operative height percentile was 53.56 27.38 , which significantly increased to $67.09 \pm 26.39$ post-operatively $(p<0.001)$. In the subgroup analysis according to preoperative height percentile, height percentile increased significantly after surgery in patients who had a pre-operative height percentile below 50. But, body mass index (BMI) percentile did not show significant difference in these pa- tients. The height percentile of patients who had pre-operative height percentile of 50 or greater also increased significantly after surgery and BMI percentile decreased in this group. Change in height percentile was greater in the group with pre-operative height percentiles below 50 compared to those with pre-operative height percentiles 50 or more $(24.11 \pm$ 21.95 vs. $5.77 \pm 21.91, p<0.001$, student's t-test) (Table 2).

Table 1. Growth and symptom change after adenotonsillectomy $(n=104)$

\begin{tabular}{|c|c|c|c|}
\hline Parameters & Pre-operative & Post-operative & $p$ value \\
\hline Mean age (years) & $6.02 \pm 1.94(3-10)$ & & \\
\hline \multicolumn{4}{|l|}{$\operatorname{Sex}(n, \%)$} \\
\hline Male & $62(59.6)$ & & \\
\hline Female & $42(40.4)$ & & \\
\hline Height percentile & $53.56 \pm 27.38$ & $67.09 \pm 26.39$ & $<0.001$ \\
\hline Weight percentile & $59.62 \pm 29.19$ & $59.58 \pm 28.63$ & 0.989 \\
\hline Body mass index percentile & $61.08 \pm 30.74$ & $54.17 \pm 28.58$ & 0.035 \\
\hline \multicolumn{4}{|l|}{ Symptom score } \\
\hline URI frequency & $3.81 \pm 2.31$ & $1.77 \pm 1.28$ & $<0.001$ \\
\hline Poor appetite & $3.35 \pm 0.73$ & $2.71 \pm 0.80$ & $<0.001$ \\
\hline Snoring or sleep apnea & $2.25 \pm 1.84$ & $0.50 \pm 0.73$ & 0.002 \\
\hline
\end{tabular}

Values are presented as mean \pm standard deviation. URI: upper respiratory infection

Table 2. Changes in height percentile

\begin{tabular}{|c|c|c|c|}
\hline Parameter & Pre-operative & Post-operative & $p$ value \\
\hline Height percentile & $53.56 \pm 27.38$ & $67.09 \pm 26.39$ & $<0.001$ \\
\hline \multicolumn{4}{|l|}{ Height percentile* $<50(n=44)$} \\
\hline Height percentile & $26.93 \pm 12.94$ & $51.05 \pm 25.78$ & $<0.001$ \\
\hline Body mass index percentile & $51.18 \pm 29.81$ & $48.09 \pm 29.61$ & 0.511 \\
\hline \multicolumn{4}{|l|}{ Height percentile* $\geq 50(n=60)$} \\
\hline Height percentile & $73.09 \pm 16.44$ & $78.86 \pm 19.97$ & 0.046 \\
\hline Body mass index percentile & $68.33 \pm 29.59$ & $58.63 \pm 27.19$ & 0.033 \\
\hline$\Delta$ Height percentile $^{\dagger}(<50)$ & \multicolumn{2}{|c|}{$24.11 \pm 21.95$} & $<0.001$ \\
\hline$\Delta$ Height percentile $^{\dagger}(\geq 50)$ & \multicolumn{2}{|c|}{$5.77 \pm 21.91$} & \\
\hline
\end{tabular}

Values are presented as mean \pm standard deviation. $*$ pre-operative height percentile, ${ }^{t}$ change in height percentile between the pre-operative and post-operative periods

Table 3. Changes in weight percentile

\begin{tabular}{|c|c|c|c|}
\hline Parameter & Pre-operative & Post-operative & $p$ value \\
\hline Weight percentile & $59.62 \pm 29.19$ & $59.58 \pm 28.63$ & 0.989 \\
\hline \multicolumn{4}{|l|}{ Weight percentile* <50 $(n=44)$} \\
\hline Weight percentile & $30.42 \pm 15.13$ & $42.62 \pm 26.43$ & 0.003 \\
\hline Body mass index percentile & $35.50 \pm 25.56$ & $45.50 \pm 27.36$ & 0.060 \\
\hline \multicolumn{4}{|l|}{ Weight percentile* $\geq 50(n=60)$} \\
\hline Weight percentile & $81.02 \pm 14.78$ & $72.02 \pm 23.44$ & 0.003 \\
\hline Body mass index percentile & $79.83 \pm 18.11$ & $60.53 \pm 27.99$ & $<0.001$ \\
\hline$\Delta$ Weight percentilet $(<50)$ & \multicolumn{2}{|c|}{$12.20 \pm 25.26$} & $<0.001$ \\
\hline$\Delta$ Weight percentilet $(\geq 50)$ & \multicolumn{2}{|c|}{$-9.01 \pm 22.71$} & \\
\hline
\end{tabular}

Values are presented as mean \pm standard deviation. $*$ pre-operative weight percentile, ${ }^{t}$ change in weight percentile between the pre-operative and post-operative periods 


\section{Changes in weight percentile}

Mean pre-operative and post-operative weight percentile were not significantly different, but weight percentile change pattern was different according to preoperative weight percentile. Weight percentile increased significantly after surgery in patients with pre-operative weight percentiles below 50 by subgroup analysis. BMI percentile also significantly increased although it didn't reach statistical significance (35.50 \pm 25.56 to $45.50 \pm 23.76, p=0.060)$. However, in patients with a pre-operative weight percentile of 50 or greater, weight percentile and BMI percentile decreased significantly. Change in weight percentile was also greater in the group with pre-operative weight percentiles below 50 (Table 3 ).

\section{Discussion}

There are many heterogeneous clinical manifestations of adenoid hypertrophy according to patient age, general condition, and nasopharynx size. The most common symptom is nasal obstruction, which can present as snoring or mouth breathing. Hypertrophied adenoids can also block the orifice of the Eustachian tube, resulting in inflammation in the middle ear, or obstruct normal ventilation of the paranasal sinuses, resulting in sinusitis. Thus, inflammatory conditions of the tonsils and adenoids tend to increase the frequency of infectious complications and the chance of contracting an upper airway infection. ${ }^{1,35}$ Adenotonsillar hypertrophy also causes snoring or sleep apnea, which result in growth retardation. ${ }^{6,8,15)}$

Adenotonsillectomy has been considered most effective treatment for adenotonsillar hypertrophy and chronic tonsillitis. Adenotonsillar hypertrophy with obstructive sleep apnea, failure to thrive, upper airway blockage and dysphagia are mainly observed in pediatric patients and candidates for adenotonsillectomy. ${ }^{16)}$

Growth improvement in children after tonsillectomy and/ or adenoidectomy have been reported by several authors. In a study conducted in 29 children with obstructive adenotonsillar hypertrophy, increased weight and height standard deviation scores, energy intake and serum insulin-like growth factor 1 (IGF-1) were reported 6 months after adenotonsillectomy. ${ }^{12)}$ A retrospective study of 115 pediatric patients with sleep apnea or recurrent tonsillitis showed that the weight and body mass index gain after adenotonsillectomy was more effective in a younger age group, especially under the age of 6 years. ${ }^{13)}$ A prospective study in 22 patients to evaluate the effect of adenotonsillectomy revealed that children that underwent adenotonsillectomy had more height and weight gain after 6 months later. ${ }^{10)}$ Recently, Katz, et al. ${ }^{11)}$ conducted randomized controlled study to compare the effect on growth of adenotonsillectomy and watchful waiting in 464 children who had obstructive sleep apnea. Their results showed that adenotonsillectomy for children with sleep apnea results in significantly greater weight gain than watchful waiting 7 months after surgery.

Growth improvement after adenotonsillectomy could be explained by several reasons including improvement of dysphagia, sleep apnea and increased growth hormone. In a study prospective study using questionnaire in 85 children who underwent tonsillectomy, swallowing related quality of life, ability to tolerate a regular diet and weight percentile for age were improved whether the reason they referred was dysphagia or not. ${ }^{17)}$ Conley, et al ${ }^{18)}$ reported improved dysphagia and sleep apnea even in children with neurologically impaired swallowing using video swallow study, polysomnography and telephone survey.

Improvement in sleep parameters including apnea/hypopnea index and minimum oxygen saturation after adenotonsillectomy in children with obstructive sleep apnea was also reported. ${ }^{19)}$ Furthermore, several studies showed that serologic changes after tonsillectomy or adenoidectmy. Increased IGF-1 mediating the anabolic effects of growth hormone and insulin-like growth factor-binding protein 3 (IGFBP-3) which is main binding protein of IGF-1 after tonsillectomy was reported. ${ }^{20,21)}$ Reduction in tumor necrosis factor- $\alpha$ (TNG- $\alpha$ ), proinflammatory cytokine, and increased CD4+/CD8+ T lymphocyte ratio after adenotonsillectomy was also reported. ${ }^{22,23)}$

However, most of the studies on growth, symptom and laboratory changes after tonsillectomy included small number of patients and short-term follow-up periods, and there have been few studies on long-term effects on growth or symptom changes.

In this study, we analyzed long-term growth changes at 5 years after adenotonsillectomy. There were significant improvements in height percentile regardless of pre-operative height percentile. Furthermore, height percentile increase was greater in patients whose pre-operative height percentile was below 50. It might imply that the growth could be markedly improved after adenotonsillectomy in children having delayed growth due to adenotonsillar disease. Weight and BMI percentile were also increased in patients whose preoperative weight percentile was below 50 . Interestingly, weight, and BMI percentile decreased in patients whose pre-opera- 
tive weight percentile was 50 or more. It can be assumed that some obese children subsequently lost their weight due to improvement of sleep-disordered breathing or decreased frequency of upper respiratory infections resulting in increased activity levels.

In the view point of preoperative symptoms, many patients had 2 or more preoperative symptoms although indication of surgery was snoring or sleep apnea in most cases. There were significant improvements in URI frequency and appetite as well as snoring or sleep apnea although preoperative presenting symptoms may be affected by many confounding factors for 5 years. We also analyzed the growth changes according to the presenting symptoms, but height percentile was significantly increased regardless of presenting symptoms.

This study has some limitations in this study. First, we investigated postoperative growth status and symptoms by telephone based survey instead of office based physical examination and survey. However, recall bias could be minimal because preoperative data was based on the medical records and the items surveyed using telephone were height, weight, and symptoms at the time of survey. Second, we assumed that children will remain on the same height and weight percentile unless they undergo adenotonsillectomy. There might be many confounding factors because the growth and symptoms could be influenced by various factors and we investigated the growth status 5 years later after surgery. However, this is an important study that showed long-term effect of adenotonsillectomy on growth because there is few study about longterm effect of adenotonsillectomy on growth.

In conclusion, adenotonsillectomy can improve snoring or sleep apnea, URI frequency and appetite for a long time. Furthermore, it has long-term positive effects on height growth in children with adenotonsillar hypertrophy. The impacts of adenotonsillectomy on growth are more prominent in patients who have lower height percentile preoperatively. Weight gain also can be expected in low-weight children before surgery.

\section{REFERENCES}

1) Brandtzaeg P. Immunology of tonsils and adenoids: everything the ENT surgeon needs to know. Int J Pediatr Otorhinolaryngol 2003; 67 Suppl 1:S69-76.

2) Siegel G. Biochemical characterization of the proliferation pool of lymphatic cells in the human tonsil and demonstration of the agedependent pool size reduction. Acta Otolaryngol 1979;87(5-6):560-6.

3) Greene MG, Carroll JL. Consequences of sleep-disordered breathing in childhood. Curr Opin Pulm Med 1997;3(6):456-63.

4) Liu J, Liu X, Ji X, Wang Y, Zhou G, Chen X. Sleep disordered breathing symptoms and daytime sleepiness are associated with emotional problems and poor school performance in children. Psychiatry Res
2016;242:218-25.

5) Marcus CL. Sleep-disordered breathing in children. Am J Respir Crit Care Med 2001:164(1):16-30.

6) Bar A, Tarasiuk A, Segev Y, Phillip M, Tal A. The effect of adenotonsillectomy on serum insulin-like growth factor-I and growth in children with obstructive sleep apnea syndrome. J Pediatr 1999; 135(1):76-80.

7) Stradling JR, Thomas G, Warley AR, Williams P, Freeland A. Effect of adenotonsillectomy on nocturnal hypoxaemia, sleep disturbance, and symptoms in snoring children. Lancet 1990;335(8684):249-53.

8) Yilmaz MD, Hoşal AS, Oğuz H, Yordam N, Kaya S. The effects of tonsillectomy and adenoidectomy on serum IGF-I and IGFBP3 levels in children. Laryngoscope 2002;112(5):922-5.

9) Bitar MA, Dowli A, Mourad M. The effect of tonsillectomy on the immune system: a systematic review and meta-analysis. Int J Pediatr Otorhinolaryngol 2015;79(8):1184-91.

10) Fernandes AA, Alcântara TA, D'Avila DV, D'Avila JS. Study of weight and height development in children after adenotonsillectomy. Braz J Otorhinolaryngol 2008;74(3):391-4.

11) Katz ES, Moore RH, Rosen CL, Mitchell RB, Amin R, Arens R, et al. Growth after adenotonsillectomy for obstructive sleep apnea: an RCT. Pediatrics 2014;134(2):282-9.

12) Selimoğlu E, Selimoğlu MA, Orbak Z. Does adenotonsillectomy improve growth in children with obstructive adenotonsillar hypertrophy? J Int Med Res 2003;31(2):84-7.

13) Smith DF, Vikani AR, Benke JR, Boss EF, Ishman SL. Weight gain after adenotonsillectomy is more common in young children. Otolaryngol Head Neck Surg 2013;148(3):488-93.

14) Korea centers for disease control and prevention. Child growth charts. [online] 2007 Oct [cited 2017 Jun 27]. Available from: http:// www.cdc.go.kr/CDC/info/CdcKrInfo0201.jsp?menuIds=HOME001MNU1154-MNU0005-MNU1889\&cid=1235.

15) Leiberman A, Stiller-Timor L, Tarasiuk A, Tal A. The effect of adenotonsillectomy on children suffering from obstructive sleep apnea syndrome (OSAS): the Negev perspective. Int J Pediatr Otorhinolaryngol 2006;70(10):1675-82.

16) Randel A. AAO-HNS guidelines for tonsillectomy in children and adolescents. Am Fam Physician 2011;84(5):566-73.

17) Clayburgh D, Milczuk H, Gorsek S, Sinden N, Bowman K, MacArthur C. Efficacy of tonsillectomy for pediatric patients with Dysphagia and tonsillar hypertrophy. Arch Otolaryngol Head Neck Surg 2011; 137(12):1197-202.

18) Conley SF, Beecher RB, Delaney AL, Norins NA, Simpson PM, Li SH. Outcomes of tonsillectomy in neurologically impaired children. Laryngoscope 2009;119(11):2231-41.

19) Costa DJ, Mitchell R. Adenotonsillectomy for obstructive sleep apnea in obese children: a meta-analysis. Otolaryngol Head Neck Surg 2009; 140(4):455-60.

20) Farmarzi M, Shishegar M, Heydari ST, Haghighi A, Sharouny H. Effects of adenotonsillectomy on serum levels of IGF-1 and IGFBP-3 and growth indices in children with adenotonsillar hypertrophy or recurrent tonsillitis. Iran J Otorhinolaryngol 2016;28(88):329-35.

21) Kiris M, Muderris T, Celebi S, Cankaya H, Bercin S. Changes in serum IGF-1 and IGFBP-3 levels and growth in children following adenoidectomy, tonsillectomy or adenotonsillectomy. Int J Pediatr Otorhinolaryngol 2010;74(5):528-31.

22) Gozal D, Serpero LD, Kheirandish-Gozal L, Capdevila OS, Khalyfa A, Tauman R. Sleep measures and morning plasma TNF-alpha levels in children with sleep-disordered breathing. Sleep 2010;33(3):319-25.

23) Yang N, Ji Y, Liu Y. Effect of transoral endoscopic adenoidectomy on peripheral blood T-lymphocyte subsets in children with obstructive sleep apnea-hypopnea syndrome and its treatment strategy. Exp Ther Med 2017;14(4):3022-8. 